\title{
The Relevance of Insulin-like Growth Factor 1 Concentration as a Screening Test for Diagnosis of Growth Hormone Deficiency
}

\author{
Aljabri KS ${ }^{1 *}$, Bokhari SA ${ }^{1}$ and Alharthi TA ${ }^{2}$ \\ ${ }^{1}$ Department of Endocrinology, King Fahad Armed Forces Hospital, Saudi Arabia \\ ${ }^{2}$ College of Medicine, Saudi Arabia
}

*Correspondence: Khalid S Aljabri, Department of Endocrinology, King Fahad Armed Forces Hospital, Saudi Arabia

Received on 05 March 2019; Accepted on 12 April 2019; Published on 23 April 2019

Copyright (c) 2019 Aljabri KS, et al. This is an open access article and is distributed under the Creative Commons Attribution License, which permits unrestricted use, distribution, and reproduction in any medium, provided the original work is properly cited.

\begin{abstract}
Objective: Growth hormone deficiency (GHD) is one of the most important endocrine and treatable causes of short stature. Insulin-like growth factor 1 (IGF-1) concentration is not recommended to establish the diagnosis of GHD. The aim of our study was to analyze the relevance of IGF-1 concentration as a screening test for the diagnosis of GHD. Materials and Methods: We retrospectively studied patients who were evaluated for short stature at the Endocrinology Department of King Fahad Armed Forces Hospital, Jeddah, Saudi Arabia from January 2015 to December 2018. For IGF-1, laboratory reference ranges were based on age and sex. For all eligible patients, IGF-1 concentration was determined and an ITT was performed. Patients with a peak GH of $\leq 5.0 \mathrm{ng} / \mathrm{ml}$ were considered to be GHD and patients with a peak $G H$ of $\geq 5.1 \mathrm{ng} / \mathrm{ml}$ were considered non-GHD (nGHD). Results: We retrospectively included 47 patients for analysis. Mean age was $14.7 \pm 1.7$ years. There were 38 males (80.9\%) and 9 females (19.1\%) and mean IGF-1 concentration was 146.4 $\pm 69.4 \mathrm{ng} / \mathrm{dl}$. Results from the ITT indicated that $27(57.4 \%)$ had GHD. Age was not significantly different between $G H D$ and non-GHD (14.7 \pm 1.8 vs. $14.8 \pm 1.6$ years, $P=0.9)$. There were non-significantly more males than females in $G H D$ patients (59\% vs. 50\%, $P=0.7)$. Mean IGF1 concentration was not significantly different $(146.9 \pm 70.4 \mathrm{ng} / \mathrm{dl} \mathrm{vs} .145 .7 \pm 69.8 \mathrm{ng} / \mathrm{dl}, \mathrm{P}=$ 0.9). IGF-1 concentration below the reference ranges for age and gender was non-significantly higher in patients with GHD compared to non-GHD (53.8\% vs. 46.2\%, P=0.8). The mean peak for $\mathrm{GH}$ concentration was significantly lower in patients with GHD $(2.2 \pm 1.3 \mathrm{ng} / \mathrm{ml}$ vs. $9.9 \pm$ $5.6 \mathrm{ng} / \mathrm{ml}, P<0.0001)$. Peak $\mathrm{GH}$ concentration was not significantly correlated with IGF-1 concentration ( $r=0.213, P=0.2$ ). We plotted a ROC curve of IGF-1 concentration according to the diagnosis of GHD as established using ITT. The AUC was 49\%. An IGF-1 threshold of $154 \mathrm{ng} / \mathrm{dl}$ was selected to emphasize sensitivity rather than specificity. With a threshold of 154 $n g / d l$, sensitivity was $52 \%$ (95\% confidence interval (95\% CI); 32\%, 71\%), specificity was $40 \%$ $(95 \% \mathrm{CI} ; 19 \%, 64 \%)$ and the negative predictive value for the diagnosis of GHD was 38\% $195 \%$ CI; 24\%, 54\%). With a threshold of $105 \mathrm{ng} / \mathrm{dl}$, the sensitivity was $41 \%$ and the specificity was 70\%. A threshold of $74 \mathrm{ng} / \mathrm{dl}$, gave a positive predictive value of $60 \%$ but a negative predictive value of $43 \% .7$ of the patients with IGF-1 concentration above the threshold of $154 \mathrm{ng} / \mathrm{dl}(\mathrm{N}=$ 20) were normal and 13 had GH deficiency. These 13 GHD patients had IGF-1 concentration that differs significantly from those of their GH-sufficient counterparts (105 \pm 35 vs. $222 \pm 49$
\end{abstract}


$n g / d l, P<0.0001$ ). If IGF-1 was used as a screening test (with a concentration threshold of 154 $\mathrm{ng} / \mathrm{dl}$ ) and ITT as a confirmatory test, 20 (43\%) out of 47 ITT would not have been performed, leading to the misdiagnosis of $13 \mathrm{GH}$-deficient adults. Thus, in our study population, such a procedure would misdiagnose 13 out of 27 GHD patients (48\%) and yield a sensitivity of 52\%. Conclusion: Many reports have already reported that IGF-1 concentration is lower in patients with GHD than in the general population, our study demonstrated the poor negative predictive value of IGF-1 concentration for the diagnosis of GHD, making it the need of the use of the "gold standard" method ITT. This observation remains to be validated by population-based studies.

Keywords: growth hormone deficiency, insulin-like growth factor 1

\section{Introduction}

Growth hormone deficiency (GHD) is one of the most important endocrine and treatable causes of short stature. GHD is associated with altered body composition and with lipoprotein and carbohydrate disorder [1,2]. The interest in the epidemiology of GHD derives from the increasing focus on patients with GHD during the last decades. This interest was spurred on by finding the positive changes in body composition of patients with GHD being treated with growth hormone (GH) [3-6]. Childhood-onset GHD has been estimated to occur in 1 per 30,000 people per year [7]. In adultonset GHD, an annual incidence of 1.2 per 100,000 adults has been estimated [8].

Insulin-like growth factor 1 (IGF-1) is the metabolic effector of GH. It is produced by the liver and is mainly controlled by GH [9]. IGF-1 concentration is not recommended to establish the diagnosis of GHD, mainly due to the overlap of IGF-1 concentrations between normal and GH-deficient subjects [10]. Dynamic tests are currently recommended for the diagnosis of GHD: the insulin tolerance test (ITT) is considered as the reference test [10-14].

Poor diagnostic accuracy of the IGF-1 concentration in patients suspected of having GHD is in keeping with reports that IGF-1 concentrations show considerable overlap between normal and GH-deficient adults. Hence, a normal IGF1 concentration does not rule out GHD. However, the presence of a low IGF-1 level in patients with hypopituitarism associated with three or more pituitary hormone deficiencies is considered highly indicative of GHD [15,16].

In our knowledge, there have been no nationwide studies using uniform diagnostic criteria. Thus, we tried to improve the simplicity and safety of the diagnosis of GHD. The use of diagnostic strategy with IGF-1 as the first screening step and the ITT as the second confirmatory step has not been studied in a population admitted on routine endocrinological practice for short stature. The aim of our study was to analyze the relevance of IGF-1 concentration as a screening test for the diagnosis of GHD.

\section{Materials and Methods}

We retrospectively studied patients who were evaluated for short stature at the Endocrinology Department of King Fahad Armed Forces Hospital, Jeddah, Saudi Arabia from January 2015 to December 2018. For IGF-1, laboratory reference ranges were based on age and sex. For all eligible patients, IGF-1 concentration was determined and an ITT was performed. The ITT consisted of the IV injection of 0.1 units of insulin $/ \mathrm{kg}$ body weight. Blood samples were collected 0 (baseline), 30, 60, 90, and 120 mins for $\mathrm{GH}$. Blood glucose concentration was also determined to ensure that the patients were hypoglycaemic if blood glucose concentration was $<2.2 \mathrm{mmol} / \mathrm{l}$. Patients with a peak GH of $\leq$ $5.0 \mathrm{ng} / \mathrm{ml}$ were considered to be GHD and patients with a peak GH of $\geq 5.1 \mathrm{ng} / \mathrm{ml}$ were considered non-GHD (nGHD). Peak GH secretion during provocative testing was used to assess the capacity of the pituitary to release GH [17]. Blood was centrifuged, and serum was frozen with dry ice until analysis by an independent laboratory. Blood glucose was determined using a glucose oxidase method. GH concentration was determined using a radioimmunometric test, with IS $80 / 505$ as the international standard. This kit was specific for $20 \mathrm{KD}$ and $22 \mathrm{KD}$ human GH. The detection limit was $0.2 \mathrm{ng} / \mathrm{ml}$. At $1.70 \mathrm{ng} / \mathrm{ml}$, intra and inter assay coefficients of variation are $3.9 \%$ and $2.3 \%$, respectively. IGF-1 concentration was determined using an immunoradiometric method (Unilabs Company, Germany). At $310 \mathrm{ng} / \mathrm{dl}$, inter and intra assay coefficients of variation were 1.3 and $3.3 \%$, respectively. 


\section{Statistical analysis}

Data has been presented as means \pm standard deviation or numbers $(\%)$. Quantitative variables were compared between the two groups by using the Student's t-test. Differences in categorical variables were analysed using the chi-square test. The relationship between continuous variables was assessed using coefficients of correlation. The ability of IGF1 concentration to discriminate between normal and GH-deficient patients was evaluated by receiver operating characteristic (ROC) curve analysis. The cut-off for optimal clinical performance measures was determined from the ROC curve. Sensitivity, specificity and positive and negative predictive values were calculated for IGF-1 and for the cascade test strategy. The optimal sensitivity and specificity using different IGF-1 cut-off values to predict the presence of GHD were examined by the receiver operating characteristic curve (ROC) analysis. A greater area under the curve (AUC) indicates better predictive capability. An AUC $=0.5$ indicates that the test performs no better than chance, and an AUC = 1.0 indicates perfect discrimination. An ideal test is one that reaches the upper left corner of the graph (100\% true positives and no false positives). To determine the optimal IGF-1 cut-off points, we computed and searched for the shortest distance between any point on the curve and the top left corner on the y-axis. The distance was estimated at each one-half unit of IGF-1 according to the equation: Distance in ROC curve $=(1 \text {-sensitivity })^{2}+(1-$ specificity $)^{2}[18,19]$. Diagnostic performance of IGF-1 in predicting GHD was assessed by calculating AUC, sensitivity, specificity, positive and negative predictive values. $\mathrm{P}$ value $<0.05$ indicates significance. The statistical analysis was conducted with SPSS version 23.0 for Windows.

\section{Results}

We retrospectively included 47 patients for analysis. Mean age was $14.7 \pm 1.7$ years (Table 1 ). There were 38 males $(80.9 \%)$ and 9 females $(19.1 \%)$ and mean IGF-1 concentration was $146.4 \pm 69.4 \mathrm{ng} / \mathrm{dl}$. Results from the ITT indicated that $27(57.4 \%)$ had GHD (Table 2). Age was not significantly different between GHD and non-GHD (14.7 \pm 1.8 vs. $14.8 \pm 1.6$ years, $\mathrm{P}=0.9)$. There were non-significantly more males than females in the GHD patients $(59 \%$ vs. $50 \%$, $\mathrm{P}=0.7)$. Mean IGF-1 concentration was not significantly different $(146.9 \pm 70.4 \mathrm{ng} / \mathrm{dl} \mathrm{vs} .145 .7 \pm 69.8 \mathrm{ng} / \mathrm{dl}, \mathrm{P}=$ 0.9). IGF-1 concentration below the reference ranges for age and gender was non-significantly higher in patients with GHD compared to non-GHD, $(53.8 \%$ vs. $46.2 \%, \mathrm{P}=0.8)$. The mean peak for $\mathrm{GH}$ concentration was significantly lower in patients with GHD $(2.2 \pm 1.3 \mathrm{ng} / \mathrm{ml}$ vs. $9.9 \pm 5.6 \mathrm{ng} / \mathrm{ml}, \mathrm{p}<0.0001)$. Peak GH concentration was not significantly correlated with IGF-1 concentration $(\mathrm{r}=0.213, \mathrm{P}=0.2)$ (Figure 1). IGF-1 concentrations according to GH deficiency status have been demonstrated (Figure 2).

We plotted a ROC curve of IGF-1 concentration according to the diagnosis of GHD as established using ITT (Figure 3). The AUC was 49\%. An IGF-1 threshold of $154 \mathrm{ng} / \mathrm{dl}$ was selected to emphasize sensitivity rather than specificity. We tested the diagnostic accuracy of several thresholds (Table 3). With a threshold of 154 ng/dl, sensitivity was 52\% (95\% confidence interval $(95 \% \mathrm{CI}) ; 32 \%, 71 \%)$, specificity was $40 \%$ (95\% CI; 19\%, 64\%) and the negative predictive value for the diagnosis of GHD was 38\% (95\% CI; 24\%, 54\%). With a threshold of $105 \mathrm{ng} / \mathrm{dl}$, the sensitivity was $41 \%$ and the specificity was $70 \%$. A threshold of $74 \mathrm{ng} / \mathrm{dl}$, gave a positive predictive value of $60 \%$ but a negative predictive value of $43 \%$.

\begin{tabular}{|l|l|l|}
\hline \multicolumn{2}{|l|}{ Parameters } & Total \\
\hline \multicolumn{2}{|l|}{ Numbers } & 47 \\
\hline \multicolumn{2}{|l|}{ Age (years) } & $14.7 \pm 1.7$ \\
\hline \multirow{2}{*}{ Gender } & Male & $38(80.9)$ \\
\cline { 2 - 3 } & Female & $9(19.1)$ \\
\hline IGF-1 (ng/dl) & $146.4 \pm 69.4$ \\
\hline
\end{tabular}

Table 1: Demographics [mean \pm standard deviation or number (\%)]. 


\begin{tabular}{|l|l|l|l|l|}
\hline \multicolumn{2}{|l|}{ Parameters } & GHD & nGHD & P value \\
\hline Numbers & $27(57.4)$ & $20(42.6)$ & \\
\hline \multirow{2}{*}{ Age (years) } & Male & $23.7 \pm 1.8$ & $14.8 \pm 1.6$ & 0.9 \\
\cline { 3 - 5 } \multirow{2}{*}{ Gender } & Female & $4(59.0)$ & $16(41.0)$ & \multirow{2}{*}{0.7} \\
\cline { 3 - 5 } IGF-1(ng/dl) & $146.9 \pm 70.4$ & $4(50.0)$ & \\
\hline GH (Peak) $(\mathrm{ng} / \mathrm{ml})$ & & $2.2 \pm 1.3$ & $9.9 \pm 5.6$ & $<0.0001$ \\
\hline
\end{tabular}

Table 2: Comparison between patients with growth hormone deficiency (GHD) and non-GHD (nGHD) [mean \pm standard deviation or number (\%)]. GH: growth hormone; IGF-1: insulin-like growth factor 1.

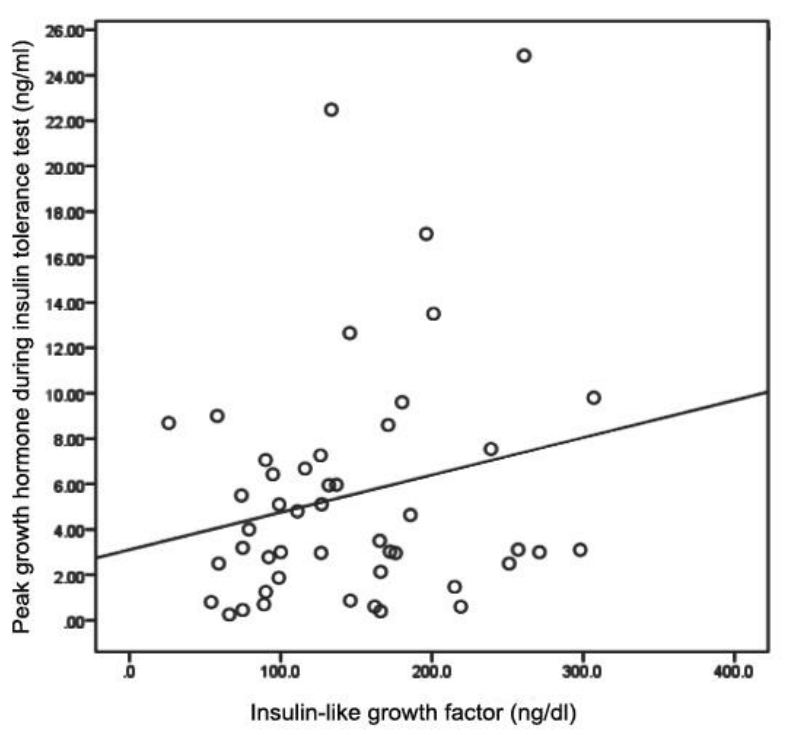

Figure 1: Correlation of insulin-like growth factor 1 concentration and growth hormone peak during insulin tolerance in the study population.

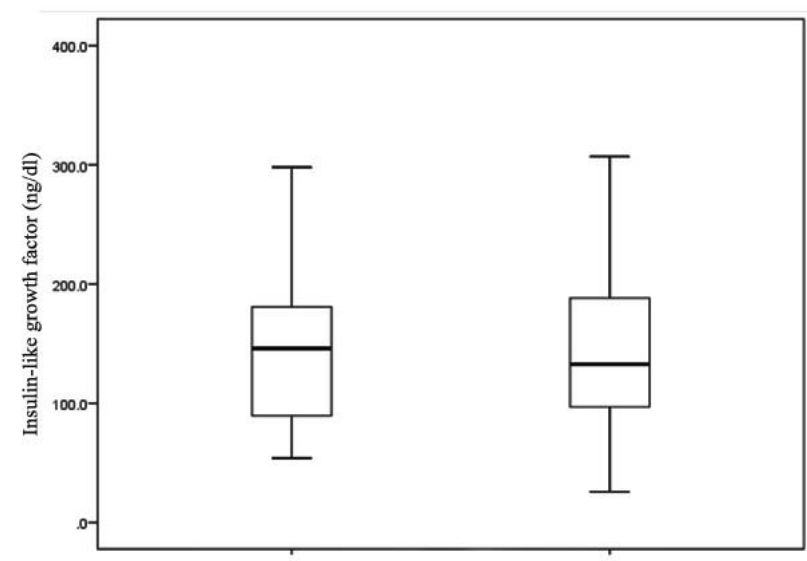

Growth hormone deficiency Non-growth hormone deficiency

Figure 2: Insulin-like growth factor 1 concentration in patients with and without growth hormone deficiency: crosses represent individual data. Boxes represent 25 th and 75 th percentiles, split by median, with error bars representing 5th and 95 th percentiles. 


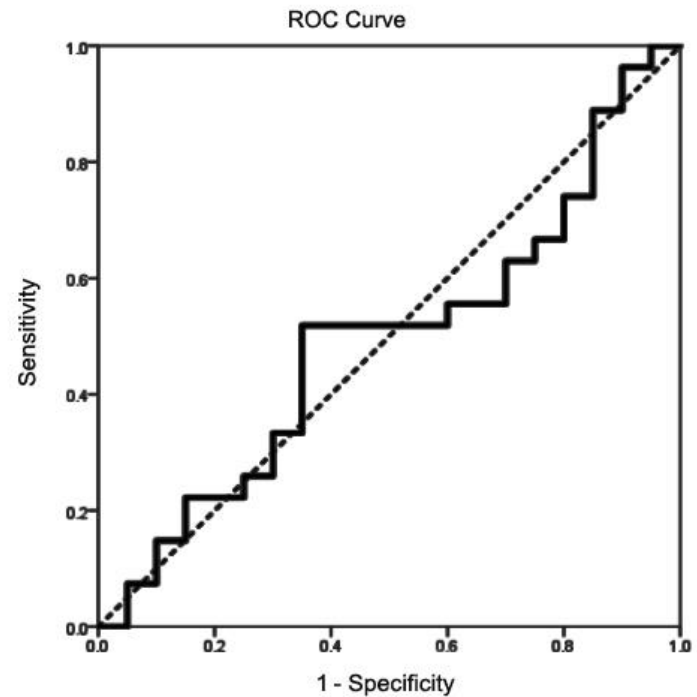

Figure 3: Receiver operating characteristic curve (ROC) of insulin-like growth factor 1 concentration, according to the diagnosis of growth hormone deficiency established using insulin tolerance test.

\begin{tabular}{|l|l|l|l|}
\hline Statistic & \multicolumn{3}{|c|}{ IGF-1 } \\
\hline & $154 \mathrm{ng} / \mathrm{dl}$ & $105 \mathrm{ng} / \mathrm{dl}$ & $74 \mathrm{ng} / \mathrm{dl}$ \\
\hline True positives & 14 & 11 & 3 \\
\hline True negatives & 7 & 14 & 18 \\
\hline False positives & 13 & 6 & 2 \\
\hline False negatives & 13 & 16 & 24 \\
\hline Sensitivity & $52(32-71)$ & $41(22-61)$ & $11(2-29)$ \\
\hline Specificity & $35(15-59)$ & $70(46-88)$ & $90(68-99)$ \\
\hline Positive Predictive Value & $52(40-64)$ & $65(45-80)$ & $60(22-89)$ \\
\hline Negative Predictive Value & $35(21-52)$ & $47(36-57)$ & $43(38-48)$ \\
\hline Accuracy & $45(30-60)$ & $53(38-68)$ & $45(30-60)$ \\
\hline
\end{tabular}

Table 3: Diagnostic performance of IGF-1 in detecting growth hormone deficiency.

7 of the patients with IGF-1 concentration above the threshold of $154 \mathrm{ng} / \mathrm{dl}(\mathrm{N}=20)$ were normal and 13 had GH deficiency. These 13 GHD patients had IGF-1 concentration that differs significantly from those of their GH-sufficient counterparts $(105 \pm 35$ vs. $222 \pm 49 \mathrm{ng} / \mathrm{dl}, \mathrm{P}<0.0001)$.

If IGF-1 was used for screening test (with a concentration threshold of $154 \mathrm{ng} / \mathrm{dl}$ ) and ITT for confirmatory test, 20 $(43 \%)$ out of 47 ITT would not have been performed, leading to the misdiagnosis of 13 GH-deficient adults. Thus, in our study population, such a procedure would have misdiagnosed 13 out of 27 GHD patients (48\%) and yield a sensitivity of $52 \%$.

\section{Discussion}

In this 3-year retrospective study, we found that IGF-1 concentration was not significantly correlated with peak GH concentration during ITT. We confirmed that IGF-1 has a poor positive predictive value for the diagnosis of GHD. However, IGF-1 thresholds at 154, 105 and $74 \mathrm{ng} / \mathrm{dl}$ were associated with a poor negative predictive value. Thus, the measurement of IGF-1 concentration, followed by a confirmatory dynamic test ITT for patients with an IGF-1 
concentration lower than $154 \mathrm{ng} / \mathrm{l}$, proved to be a valid approach. We also observed a non-significant negative correlation between age and IGF-1 concentration, as in many reports $(r=-0.1, \mathrm{P}=0.5)[11,20,21]$.

The diagnostic procedure we propose here was developed to limit the use of ITT which can result in adverse reactions typical of symptomatic hypoglycemia. We chose a very feasible method with large access: IGF-1 determination. It has been shown, in large groups of patients with adult GHD, that IGF-1 concentration (adjusted for age and sex) is low in a very high proportion of GHD cases [20-22]. This is in disconcordance with our findings: only 13 out of 27 subjects with GHD had an IGF-1 concentration higher than the threshold we selected.

The clinical relevance of our diagnostic strategy is of clinical importance. This approach could not distinguish individuals with GHD from individuals without GHD which affects therapeutic options, as GHD patients can be treated with recombinant $\mathrm{GH}$, which may improve the height and quality of life $[23,24]$. We were concerned by the imperfect diagnostic performance of the cascade test; it misdiagnosed 13/27 patients, meaning that these 13 patients would have been denied for recombinant GH treatment. However, the titration of recombinant GH treatment aims to obtain normal IGF-1 concentrations, which is already the case for these patients. Furthermore, these patients could be the least likely to benefit from recombinant human GH treatment as suggested by their normal IGF-1 concentration although this is disputed by others [25-27].

Interestingly, the diagnostic procedure using a very low threshold for IGF-1 is associated with a $60 \%$ positive predictive value [16]. With this threshold, 2 out of 5 patients would have been misclassified as GHD in our study population. We believe that our diagnostic procedure (i.e. IGF-1 threshold of $154 \mathrm{ng} / \mathrm{ml}$ ) is safer than that with the low threshold $(74 \mathrm{ng} / \mathrm{ml}$ ) because even if some patients would not have access to $\mathrm{GH}$, despite being potential candidates for this treatment, all candidates for GH treatment identified by the cascade test approach had effective GHD. Conversely, with the low threshold procedure, some patients with normal GH function would receive GH therapy, which is not indicated currently.

Some limitations must be acknowledged. This is a single center study, with a small number of patients. However, the study population is not selected at variance with other reports on the same topic similar to those studied in other largescale cohorts [28]. We had to rely on IGF-1 concentration and not on IGFBP-3, which has been reported to be of greater diagnostic value by some, but not all authors [29-32]. A second limitation is that the IGF-1 threshold concentration (154 ng/dl) did not take age and sex into account. Thirdly, IGF-1 concentration could vary greatly as shown in normal volunteers [33]. Thus, the threshold of $154 \mathrm{ng} / \mathrm{ml}$ could be crossed due to this variability. However, this drawback can be overcome if IGF-1 is assessed regularly (i.e. yearly). Coupled with ITT in a diagnostic strategy such as what is proposed here, this variability will not lead to inappropriate GH therapy, but simply to a possible delay of active treatment.

In conclusion, many reports have already reported that IGF-1 concentration is lower in patients with GHD than in the general population, our study demonstrated the poor negative predictive value of IGF-1 concentration for the diagnosis of GHD, making it the need for the use of the "gold standard" method ITT. This observation remains to be validated by population-based studies.

\section{Conflicts of Interest}

The authors declare no conflicts of interest.

\section{Acknowledgments}

The author would like to thank all colleagues from the Department of Endocrinology for helping in data collection.

\section{References}

1. De Boer H, Blok GJ, Van der Veen EA. Clinical aspects of growth hormone deficiency in adults. Endocr Rev. 1995;16(1):63-86.

2. Amato G, Carella C, Fazio S, et al. Body composition, bone metabolism, and heart structure and func- tion 
in growth hormone $(\mathrm{GH})$-deficient adults before and after $\mathrm{GH}$ replacement therapy at low doses. J Clin Endocrinol Metab. 1993;77(6):1671-76.

3. Novak LP, Hayles AB, Cloutier MD. Effect of HGH on body composition of hypopituitary dwarfs. Fourcompartment analysis and composite body density. Mayo Clin Proc. 1972;47(4):241-46.

4. Rosenbaum M, Gertner JM, Leibel RL. Effects of systemic growth hormone (GH) administration on regional adipose tissue distribution and metabolism in GH-deficient children. J Clin Endocrinol Metab. 1989;69(6):1274-81.

5. Jorgensen JO, Pedersen SA, Thuesen L, et al. Beneficial effects of growth hormone treatment in GH-deficient adults. Lancet. 1989;1(8469):1221-25.

6. Salomon F, Cuneo RC, Hesp R, et al. The effects of treatment with recombinant human growth hormone on body composition and metabolism in adults with growth hormone deficiency. N Engl J Med. 1989;321(26):1797-803.

7. Parkin JM. Incidence of growth hormone deficiency. Arch Dis Child. 1974;49(11):904-05.

8. Sassolas G, Chazot FB, Jaquet P, et al. GH deficiency in adults: an epidemiological approach. Eur J Endocrinol. 1999;141(6):595-600.

9. Hilding A, Hall K, Wivall-Helleryd IL, et al. Serum levels of insulin-like growth factor I in 152 patients with growth hormone deficiency, aged 19-82 years, in relation to those in healthy subjects. J Clin Endocrinol Metab. 1999;84(6):2013-19.

10. Consensus guidelines for the diagnosis and treatment of adults with growth hormone deficiency: summary statement of the Growth Hormone Research Society Workshop on Adult Growth Hormone Deficiency. J Clin Endocrinol Metab. 1998;83(2):379-81.

11. Hoffman DM, O’Sullivan AJ, Baxter RC, et al. Diagnosis of growth- hormone deficiency in adults. Lancet. 1994;343(8905):1064-68.

12. Ghigo E, Masel B, Aimaretti G, et al. Consensus guidelines on screening for hypopituitarism following traumatic brain injury. Brain Inj. 2005;19(9): 711-24.

13. Cansanuev FF, Castro AI, Micic D, et al. New guidelines for the diagnosis of growth hormone deficiency in adults. Horm Res. 2009;71(Suppl 1) :112-15.

14. Biller BM, Samuels MH, Zagar A, et al. Sensitivity and specificity of six tests for the diagnosis of adult GH deficiency. J Clin Endocrinol Metab. 2002;87(5):2067-79.

15. Toogood AA, Beardwell CG, Shalet SM. The severity of growth hormone deficiency in adults with pituitary disease is related to the degree of hypopituitarism. Clin Endocrinol (Oxf). 1994;41(4) :511-16.

16. Hartman ML, Crowe BJ, Biller BM, et al. Which patients do not require a GH stimulation test for the diagnosis of adult GH deficiency? J Clin Endocrinol Metab. 2002 ;87(2):477-85.

17. Zgaljardic DJ, Guttikonda S, Grady JJ, et al. Serum IGF-1 concentrations in a sample of patients with traumatic brain injury as a diagnostic marker of growth hormone secretory response to glucagon stimulation testing. Clin Endocrinol (Oxf). 2011;74(3):365-69.

18. Zhu S, Wang Z, Heshka S, et al. Waist circumference and obesity-associated risk factors among whites in the third National Health and Nutrition Examination Survey: Clinical action thresholds. Am J Clin Nutr. 2002;76(4):743-49. 
19. Weng X, Liu Y, Ma J, et al. Use of body mass index to identify obesity-related metabolic disorders in the Chinese population. Eur J Clin Nutr. 2006;60(8):931-37.

20. Shalet SM, Toogood A, Rahim A, et al. The diagnosis of growth hormone deficiency in children and adults. Endocr Rev. 1998;19(2):203-23.

21. Toogood AA, O’Neill PA, Shalet SM. Beyond the somatopause: growth hormone deficiency in adults over the age of 60 years. J Clin Endocrinol Metab. 1996;81(2):460-65.

22. Aimaretti G, Corneli G, Baldelli R, et al. Diagnostic reliability of a single IGF-I measurement in 237 adults with total anterior hypopituitarism and severe GH deficiency. Clin Endocrinol (Oxf). 2003;59(1):56-61.

23. Carroll PV, Christ ER, Bengtsson BA, et al. Growth hormone deficiency in adulthood and the effects of growth hormone replacement: a review. Growth Hormone Research Society Scientific Committee. J Clin Endocrinol Metab. 1998;83(2):382-95.

24. Deyo RA, Jarvik JJ. New diagnostic tests: breakthrough approaches or expensive add-ons? Ann Intern Med. 2003;139(11):950-51.

25. 25. Abrahamsen B, Nielsen TL, Hangaard J, et al. Dose-, IGF-I- and sex-dependent changes in lipid profile and body composition during GH replacement therapy in adult onset GH deficiency. Eur J Endocrinol. 2004;150(5):671-6 9.

26. Murray RD, Wieringa GE, Lissett CA, et al. Low-dose GH replacement improves the adverse lipid profile associated with the adult GH deficiency syndrome. Clin Endocrinol (Oxf). 2002;56(4):525-32.

27. Ahmad AM, Hopkins MT, Thomas J, et al. Body composition and quality of life in adults with growth hormone deficiency; effects of low-dose growth hormone replacement. Clin Endocrinol (Oxf). 2001;54(6):709-17.

28. Boquete HR, Sobrado PG, Fideleff HL, et al. Evaluation of diagnostic accuracy of insulin-like growth factor (IGF)-I and IGF-binding protein-3 in growth hormone-deficient children and adults using ROC plot analysis. J Clin Endocrinol Metab. 2003;88(10):4702-08.

29. Cianfarani S, Boemi S, Spagnoli A, et al. Is IGF binding protein-3 assessment helpful for the diagnosis of GH deficiency? Clin Endocrinol (Oxf). 1995;43(1):43-7.

30. Granada ML, Murillo J, Lucas A, et al. Diagnostic efficiency of serum IGF-I, IGF-binding protein-3 (IGFBP3), IGF-I/IGFBP-3 molar ratio and urinary GH measurements in the diagnosis of adult GH deficiency: importance of an appropriate reference population. Eur J Endocrinol. 2000;142(3):243-53.

31. Marzullo P, Di Somma C, Pratt KL, et al. Usefulness of different biochemical markers of the insulin-like growth factor (IGF) family in diagnosing growth hormone excess and deficiency in adults. J Clin Endocrinol Metab. 2001;86(7):3001-08.

32. Juul A, Moller S, Mosfeldt-Laursen E, et al. The acid-labile subunit of human ternary insulin-like growth factor binding protein complex in serum: hepatosplanchnic release, diurnal variation, circulating concentrations in healthy subjects, and diagnostic use in patients with growth hormone deficiency. J Clin Endocrinol Metab. 1998;83(12):4408-15.

33. Milani D, Carmichael JD, Welkowitz J, et al. Variability and reliability of single serum IGF-I measurements: impact on determining predictability of risk ratios in disease development. J Clin Endocrinol Metab. 2004;89(5):2271-74. 